\title{
Association between MMP3 and TIMP3 polymorphisms and risk of osteoarthritis
}

\author{
Zhichao Tong ${ }^{1, *}$, Yang Liu ${ }^{2, *}$, Bo Chen ${ }^{1}$, Liang Yan ${ }^{3}$ and Dingjun $\mathrm{Hao}^{3}$ \\ ${ }^{1}$ Department of Bone Diesase and Bone Tumor, Hong Hui Hospital, Xi'an Jiaotong University College of Medicine, Shaanxi \\ 710054, China \\ ${ }^{2}$ Department of Orthopaedics, Hong Hui Hospital, Xi'an Jiaotong University College of Medicine, Shaanxi 710054, China \\ ${ }^{3}$ Department of Spinal Surgery, Hong Hui Hospital, Xi'an Jiaotong University College of Medicine, Shaanxi 710054, China \\ *These authors have contributed equally to this work and should be considered as co-first authors \\ Correspondence to: Liang Yan, email: liangyanhonghvi@163.com \\ Dingjun Hao, email: dingjunhaohonghvi@163.com
}

Keywords: MMP-3, TIPM-3, osteoarthritis, polymorphisms

Received: December 21,2016 Accepted: March 08, $2017 \quad$ Published: June 27, 2017

Copyright: Tong et al. This is an open-access article distributed under the terms of the Creative Commons Attribution License 3.0 (CC BY 3.0), which permits unrestricted use, distribution, and reproduction in any medium, provided the original author and source are credited.

\section{ABSTRACT}

\begin{abstract}
Osteoarthritis (OA) is the most commonly occurring degenerative joint disease worldwide, and its incidence has increased in recent years. We evaluated whether there is the association between MMP-3 and TIMP-3 variants and susceptibility to $O A$ in a Chinese population. Venous blood samples were collected from 431 female participants (200 cases and 231 controls) at Hong Hui Hospital, Xi'an Jiaotong University College of Medicine between 2015 and 2016. After genotyping the samples using standard protocols, the association between MMP-3 and TIMP-3 single nucleotide polymorphisms and risk of OA was assessed by calculating odds ratios (ORs) and $95 \%$ confidence intervals (95\% CIs) using unconditional logistic regression analysis. The minor $G$ allele of rs650108 was associated with OA risk in a recessive model ( $p$ $=0.034, \mathrm{OR}=1.82,95 \% \mathrm{CI}=1.04-3.18)$, while the minor $\mathrm{A}$ allele of rs715572 was associated with OA risk in a recessive model $(p=0.030, \mathrm{OR}=1.88,95 \% \mathrm{CI}=1.05-$ 3.34). Thus a suggestive association was observed in a discovery case-control study between OA and two common SNPs, rs650108 in MMP-3 and rs715572 in TIMP-3.
\end{abstract}

\section{INTRODUCTION}

Osteoarthritis (OA) is the most commonly occurring degenerative joint disease worldwide [1]. Affecting primarily middle-aged and older individuals, its incidence has been increasing in recent years. OA patients (especially older adults) are characterized by narrowing of the joint line in such joints as the hip joint, knee or small joints of the hand, foot, and spine, accompanied with progressively greater loads on the subchondral bone, which results in late-onset articular cartilage cataplasia, joint pain and joint stiffness $[2,3]$. Previous epidemiological findings suggest that one-third of elderly adults $(\geq 65)$ suffer from OA. In addition, several recent studies have shown that both environmental and genetic factors contribute to OA $[4,5]$.

Much of our current knowledge about OA has come from molecular genetic investigations [6, 7]. Genome- wide association studies have demonstrated that OA susceptibility is influenced by genetic predisposition. When we searched for susceptibility loci for OA, it was apparent that many loci have particular relevance for the development of OA at particular skeletal sites, and many of the linkages to OA differed depending on the ethnicity of the patient [8-10]. A search of the U. S. National Library of Medicine database (MEDLINE) (http://www.ncbi.nlm.nih.gov/IEB/Research/Acembly/ av.cgi) for genetic information focusing on the relationship between genetic variation and disease reported that matrix metalloproteinase-3 gene (MMP-3) and the tissue inhibitors of matrix metalloproteinases-3 gene (TIMP3) associated with rheumatoid arthritis and arthritis. Putative interactions between TIMP-3 and MMP-3 proteins were also reported [11-13]. MMP-3 and TIMP-3 have also been shown to be involved in a variety of other ailments, 
including prostate cancer, ulcerative colitis and abdominal aortic aneurysm [14-16]. Moreover, compelling evidence suggests that MMP3 and TIMP-3 polymorphisms may contribute to OA $[17,18]$.

MMPs are a large family of extracellular zincdependent endopeptidases that catalyze the production and degradation of extracellular matrix (ECM) under both physiological and pathological conditions, while TIMPs function as MMP inhibitors [19, 20]. Consequently, TIMPs act as key regulators of bone metabolism [17, 21]. One previous study reported TIMP-3 is expressed in osteoblasts, and that its expression is up-regulated during differentiation of MC3T3-E1 cells. In addition, the expression of osteocalcia, osteonectin, and osteopontin are all inhibited by overexpression of TIMP-3 [22]. Hence, MMP-3 and TIMP-3 are important mediators for osteoblast function.

In the present study, we investigated whether allelic variants of $M M P-3$ and TIMP-3 associate with OA. We selected 12 single nucleotide polymorphisms (SNPs) and performed a comprehensive association analysis with OA. Our risk analysis revealed a suggestive association between OA and two common SNPs.

\section{RESULTS}

In total, 431 female subjects were genotyped (200 cases and 231 healthy controls) for 12 SNPs. The mean age of the cases was significantly greater than that of the controls (59.3 vs. 54.0 years, $p<0.001)$ (Table 1$)$.

Table 2 summarizes the MAF, Hardy-Weinberg equilibrium $p$ values, and Pearson's $\chi^{2} p$ values for the 12 SNPs examined in this study population. Although no SNPs were outside the HWE $(p<0.05)$, Pearson's $\chi^{2}$ analysis revealed that 4 SNPs were not associated with OA $(p<0.05$ for both).

Table 3 lists the associations between the $M M P-3$ and TIMP-3 SNPs and OA risk in co-dominant, dominant, and recessive models. The minor $\mathrm{G}$ allele of rs650108 in $M M P-3$ was associated with OA risk in the recessive model $(p=0.034$, OR $=1.82,95 \% \mathrm{CI}=1.04-3.18)$, while the minor A allele of rs715572 in TIMP-3 was associated with OA risk in the recessive model $(p=0.03, \mathrm{OR}=1.88$, $95 \% \mathrm{CI}=1.05-3.34)$.

\section{DISCUSSION}

MMP-3 is a zinc-dependent endopeptidase that catalyzes the degradation of various collagenous, ECM and non-collagenous basement membrane proteins [23]. In addition, MMP-3 cleaves the propeptide unit to activate other MMPs. Consequently, the MMP-3 substrate profile crucially affects matrix degradation and remodeling within normal and diseased musculoskeletal soft tissues [23, 24]. Our results showed that there is a weak association between MMP-3 SNPs and OA susceptibility. Although these gene variants were previously associated with cartilage and tendon pathology risk, no association between $M M P-3$ SNPs and the degeneration of knee articular cartilage or patellar tendon have been reported [25].

TIMP-3 is TIMP family member that displays unique molecular properties and features. For example, TIMP-3 appears able to induce apoptosis in melanoma cells, retinal pigment epithelial cells, and breast cancer cells [26-28]. TIMP-3 also acts as a local cytokine in bone, regulating bone metabolism by suppressing osteoblast differentiation and inducing osteoblast apoptosis [29, 30]. In addition, TIMP-3 variants were weakly associated with OA susceptibility in our study.

The participants in the present study were genetically unrelated native residents in Xi'an, Shaanxi Province. All individuals were in Hardy-Weinberg equilibrium and were ethnically homogeneous, which made confounding ethnic heterogeneity less likely. The likely reasons some previous studies did not detect significant evidence of an association between $M M P-3$ or TIMP-3 SNPs and susceptibility to OA are that (a) the studies were limited by the small sample size or (b) there was heterogeneity among the study populations further complicated by the allelic frequencies in the various susceptibility genes [31].

There is functional evidence for the role of $M M P$ 3 in OA, which makes it an interesting study target, even though this gene is not the main $M M P$ related to OA. MMP-3 is the main MMP family member involved in cartilage degradation, and is thought to have broad substrate specificity enabling to be active against types II, III, and IV collagens, laminin, proteoglycans, and fibronectin. Moreover, MMP-3 is able to activate MMP1, MMP-2, MMP-9 and MMP-13 [32, 33]. An earlier study reported that levels of MMP-3 in the synovial fluid and serum are elevated in canine models of OA $[34,35]$. In addition, the major histocompatibility complex (MHC) can present the fragments generated through MMP-3-catalyzed collagen hydrolysis to $\mathrm{T}$ cells, and promote the activation and release of inflammatory cytokines, which in turn increase $M M P$ 3 expression in cartilage cells and synovial fibroblasts. These processes result in increased collagenase activity and aggravation of joint inflammation [36]. Similarly, functional evidence for the role of TIMP-3 in OA also makes it an interesting study target for OA. TIMP-3 is reported to be highly expressed in the endosteal region of bone marrow, particularly by osteoblasts, and to regulate hematopoietic stem cell proliferation (HSC), differentiation and trafficking in vivo, as well as bone turnover. TIMP-3 is also expressed by stromal cells forming HSC niches within the bone marrow. TIMP-3 
Table 1: Characteristics of cases and controls in this study

\begin{tabular}{lccc}
\hline Variable & Normal(n=231) & OA(n=200) & P-value \\
\hline Age(SD), year & $54.0(9.3)$ & $59.3(3.6)$ & $<0.001$ \\
Female & 231 & 200 & - \\
\hline
\end{tabular}

Table 2: Allele frequencies in cases and controls and odds ratio estimates for osteoarthritis

\begin{tabular}{|c|c|c|c|c|c|c|c|c|}
\hline \multirow[t]{2}{*}{ Gene } & \multirow[t]{2}{*}{ rs number } & \multirow[t]{2}{*}{ Role } & \multirow[t]{2}{*}{ allele $\left(\mathbf{A}^{1 /} \mathbf{B}\right)$} & \multicolumn{2}{|c|}{$\begin{array}{l}\text { Major allelic } \\
\text { frequency }\end{array}$} & \multirow[t]{2}{*}{ HWE $P$ value $^{2}$} & \multirow[t]{2}{*}{ OR(95\%CI) } & \multirow[t]{2}{*}{ P-value } \\
\hline & & & & case & control & & & \\
\hline \multirow[t]{8}{*}{ MMP3 } & rs639752 & Intron & $\mathrm{C} / \mathrm{A}$ & 0.33 & 0.31 & 0.09 & $1.10(0.82-1.46)$ & 0.53 \\
\hline & rs650108 & Intron & $\mathrm{G} / \mathrm{A}$ & 0.41 & 0.37 & 0.07 & $1.20(0.91-1.57)$ & 0.20 \\
\hline & rs 520540 & Coding exon & $\mathrm{A} / \mathrm{G}$ & 0.33 & 0.31 & 0.09 & $1.10(0.82-1.46)$ & 0.53 \\
\hline & rs646910 & Intron & $\mathrm{A} / \mathrm{T}$ & 0.08 & 0.06 & 0.15 & $1.41(0.82-2.42)$ & 0.21 \\
\hline & rs602128 & Coding exon & $\mathrm{A} / \mathrm{G}$ & 0.33 & 0.30 & 0.21 & $1.14(0.85-1.52)$ & 0.38 \\
\hline & rs679620 & Coding exon & $\mathrm{T} / \mathrm{C}$ & 0.33 & 0.31 & 0.13 & $1.10(0.82-1.45)$ & 0.57 \\
\hline & rs678815 & Intron & $\mathrm{G} / \mathrm{C}$ & 0.32 & 0.31 & 0.13 & $1.04(0.78-1.40)$ & 0.79 \\
\hline & rs522616 & Promoter & $\mathrm{C} / \mathrm{T}$ & 0.41 & 0.41 & 0.06 & $1.00(0.76-1.32)$ & 0.98 \\
\hline \multirow[t]{4}{*}{ TIMP3 } & rs 715572 & Intron & $\mathrm{A} / \mathrm{G}$ & 0.38 & 0.32 & 0.65 & $1.30(0.99-1.72)$ & 0.06 \\
\hline & rs8136803 & Intron & $\mathrm{T} / \mathrm{G}$ & 0.04 & 0.05 & 1.00 & $0.83(0.43-1.60)$ & 0.59 \\
\hline & rs9609643 & Intron & $\mathrm{A} / \mathrm{G}$ & 0.13 & 0.15 & 0.61 & $0.85(0.58-1.25)$ & 0.41 \\
\hline & rs 11547635 & Coding exon & $\mathrm{T} / \mathrm{C}$ & 0.33 & 0.37 & 0.07 & $0.84(0.63-1.11)$ & 0.21 \\
\hline
\end{tabular}

${ }^{1}$ Minor allele; ${ }^{2}$ Site with HWE $\mathrm{P} \leq 0.05$ excluded. HWE: Hardy-Weinberg equilibrium.

Table 3: Logistic regression analysis of the association between single-nucleotide polymorphisms and osteoarthritis risk $\mathrm{n}(\%)$

\begin{tabular}{|c|c|c|c|c|c|c|c|c|}
\hline SNP & Model & Genotype & Group $=$ control & Group $=$ case & OR $(95 \% \mathrm{CI})$ & P-value & AIC & BIC \\
\hline \multirow[t]{8}{*}{ rs650108 } & \multirow{3}{*}{ Codominant } & $\mathrm{A} / \mathrm{A}$ & $86(37.4 \%)$ & $72(36 \%)$ & 1 & \multirow[t]{3}{*}{0.098} & \multirow[t]{3}{*}{595.4} & \multirow[t]{3}{*}{607.6} \\
\hline & & $\mathrm{A} / \mathrm{G}$ & $120(52.2 \%)$ & $93(46.5 \%)$ & $0.93(0.61-1.40)$ & & & \\
\hline & & $\mathrm{G} / \mathrm{G}$ & $24(10.4 \%)$ & $35(17.5 \%)$ & $1.74(0.95-3.19)$ & & & \\
\hline & \multirow{2}{*}{ Dominant } & $\mathrm{A} / \mathrm{A}$ & $86(37.4 \%)$ & $72(36 \%)$ & 1 & \multirow{2}{*}{0.770} & \multirow{2}{*}{597.9} & \multirow{2}{*}{606.1} \\
\hline & & $\mathrm{A} / \mathrm{G}-\mathrm{G} / \mathrm{G}$ & $144(62.6 \%)$ & $128(64 \%)$ & $1.06(0.72-1.57)$ & & & \\
\hline & \multirow{2}{*}{ Recessive } & $\mathrm{A} / \mathrm{A}-\mathrm{A} / \mathrm{G}$ & $206(89.6 \%)$ & $165(82.5 \%)$ & 1 & \multirow{2}{*}{0.034} & \multirow{2}{*}{593.5} & \multirow{2}{*}{601.6} \\
\hline & & $\mathrm{G} / \mathrm{G}$ & $24(10.4 \%)$ & $35(17.5 \%)$ & $1.82(1.04-3.18)$ & & & \\
\hline & \multirow{3}{*}{ Codominant } & $\mathrm{G} / \mathrm{G}$ & $104(45 \%)$ & $80(40 \%)$ & 1 & & & \\
\hline \multirow[t]{6}{*}{ rs715572 } & & $\mathrm{G} / \mathrm{A}$ & $105(45.5 \%)$ & $87(43.5 \%)$ & $1.08(0.72-1.62)$ & \multirow[t]{2}{*}{0.090} & \multirow[t]{2}{*}{596.4} & \multirow[t]{2}{*}{608.6} \\
\hline & & $\mathrm{A} / \mathrm{A}$ & $22(9.5 \%)$ & $33(16.5 \%)$ & $1.95(1.06-3.60)$ & & & \\
\hline & \multirow{2}{*}{ Dominant } & $\mathrm{G} / \mathrm{G}$ & $104(45 \%)$ & $80(40 \%)$ & 1 & \multirow{2}{*}{0.290} & \multirow{2}{*}{598.2} & \multirow{2}{*}{606.3} \\
\hline & & $\mathrm{G} / \mathrm{A}-\mathrm{A} / \mathrm{A}$ & $127(55 \%)$ & $120(60 \%)$ & $1.23(0.84-1.80)$ & & & \\
\hline & \multirow{2}{*}{ Recessive } & G/G-G/A & $209(90.5 \%)$ & $167(83.5 \%)$ & 1 & \multirow{2}{*}{0.030} & \multirow{2}{*}{594.6} & \multirow{2}{*}{602.7} \\
\hline & & $\mathrm{A} / \mathrm{A}$ & $22(9.5 \%)$ & $33(16.5 \%)$ & $1.88(1.05-3.34)$ & & & \\
\hline
\end{tabular}

AIC: Akaike's information criterion; BIC: Bayesian information criterion; SNP: Single-nucleotide polymorphism. 
Table 4: Primers used for this study

\begin{tabular}{|c|c|c|c|}
\hline SNP_ID & 1st-PCRP & 2nd-PCRP & UEP_SEQ \\
\hline rs639752 & $\begin{array}{l}\text { ACGTTGGATGCAGAT } \\
\text { AAATTCTCCACTTGC }\end{array}$ & $\begin{array}{c}\text { ACGTTGGATGGGCTGCA } \\
\text { ATGCAGGGAAAAG }\end{array}$ & tGGGAAGAAAGAAATAGGTGAT \\
\hline rs650108 & $\begin{array}{c}\text { ACGTTGGATGGTCA } \\
\text { CTGTCTCATTGTGTGT }\end{array}$ & $\begin{array}{c}\text { ACGTTGGATGTCAGGT } \\
\text { AGAGGTGACAAGTG }\end{array}$ & tAAGTGGGTGAGGTTAGA \\
\hline rs520540 & $\begin{array}{l}\text { ACGTTGGATGGCGAA } \\
\text { AGGGCTTAACTGTTAT }\end{array}$ & $\begin{array}{c}\text { ACGTTGGATGCCAGCT } \\
\text { CGTACCTCATTTCC }\end{array}$ & CTCGTACCTCATTTCCTCTGAT \\
\hline rs646910 & $\begin{array}{c}\text { ACGTTGGATGCCAC } \\
\text { TGTAAGCTGGTGACTA }\end{array}$ & $\begin{array}{c}\text { ACGTTGGATGGTTA } \\
\text { AGCCCTTTCGCTTTAG }\end{array}$ & CGCTTTAGAAATACACTTTAGCATCT \\
\hline rs602128 & $\begin{array}{c}\text { ACGTTGGATGCTTC } \\
\text { GGGATGCCAGGAAA }\end{array}$ & $\begin{array}{l}\text { ACGTTGGATGAAGCT } \\
\text { GGACTCCGACACTCT }\end{array}$ & CAGGTGTGGAGTTCCTGA \\
\hline rs679620 & $\begin{array}{c}\text { ACGTTGGATGAACAGG } \\
\text { ACCACTGTCCTTTC }\end{array}$ & $\begin{array}{c}\text { ACGTTGGATGAGA } \\
\text { AATATCTAGAAAACTAC }\end{array}$ & tcTCTAGAAAACTACTACGACCTC \\
\hline rs678815 & $\begin{array}{c}\text { ACGTTGGATGAATGCA } \\
\text { ACGTAATTTTAGC }\end{array}$ & $\begin{array}{c}\text { ACGTTGGATGTGGA } \\
\text { GTATTTCTCTAGCTTG }\end{array}$ & TCTCTAGCTTGCTGAAATAATG \\
\hline rs522616 & $\begin{array}{l}\text { ACGTTGGATGCGTAG } \\
\text { CTGCTCCATAAATAG }\end{array}$ & $\begin{array}{l}\text { ACGTTGGATGACAGA } \\
\text { GAGAATTTCAGTCCG }\end{array}$ & gaCGGTAAGCAATGTAATTCATTTCA \\
\hline rs715572 & $\begin{array}{c}\text { ACGTTGGATGTAGTGA } \\
\text { GTGTCCAAGGAACC }\end{array}$ & $\begin{array}{c}\text { ACGTTGGATGAA } \\
\text { GCTAGTCCACCTCTCTTC }\end{array}$ & СТСТСТTТСТTССAGCA \\
\hline rs8136803 & $\begin{array}{c}\text { ACGTTGGATGTGGCAC } \\
\text { ATAACAGGCACCTC }\end{array}$ & $\begin{array}{c}\text { ACGTTGGATGCTG } \\
\text { TGTGTGGCACTTTATAC }\end{array}$ & TGGCACTTTATACAAGAAATCACAC \\
\hline rs9609643 & $\begin{array}{c}\text { ACGTTGGATGTGAA } \\
\text { GAGATGTCTGGCTTTG }\end{array}$ & $\begin{array}{l}\text { ACGTTGGATGGTCCC } \\
\text { AAGGGTTTATAATAG }\end{array}$ & ATAGGAAAATGCCTCTACTTTA \\
\hline rs11547635 & $\begin{array}{c}\text { ACGTTGGATGTGCC } \\
\text { CCATGTGCAGTACATC }\end{array}$ & $\begin{array}{c}\text { ACGTTGGATGACTG } \\
\text { GTACTTGTTGACCTCC }\end{array}$ & tGCTTAAGGCCACAGAGACTCTC \\
\hline
\end{tabular}

may thus be involved in regulating both hematopoiesis and bone remodeling.

\section{CONCLUSIONS}

The present case-control study revealed a suggestive association between $\mathrm{OA}$ and two common SNPs, rs650108 and rs715572, in MMP-3 and TIMP-3, respectively. Both of these genes were previously reported to have a functional role in OA but the finding was not replicated with statistical significance in follow-up analyses of OA.

\section{MATERIALS AND METHODS}

\section{Ethics statement}

The study was approved by the Ethics Committee of Hong Hui Hospital, Xi' an Jiaotong University College of Medicine. An investigative agreement and a standard statistical survey questionnaire were drafted which followed the World Medical Association Declaration of Helsinki. The primary protocols were explained to each participant before they signed an informed consent.

\section{Subjects}

Venous blood samples were collected from 431 female participants (200 cases and 231 controls) at the Orthopedics and Medical Examination Center at Hong Hui Hospital, Xi'an Jiaotong University College of Medicine between 2015 and 2016. All participants were native residents in Xi'an, Shaanxi Province, and all were genetically unrelated. We diagnosed OA based on the American College of Rheumatology criteria. These included primary OA with any symptoms in one or two knees and radiographic signs of OA graded as $\geq 2$ on the Kellgren-Lawrence (K/L) grading system. We excluded the controls with post-traumatic or post-septic arthritis, skeletal or developmental aldysplasia, and inflammatory arthritis. The closing date of eligibility was June 31, 2016, at which time we have enough patients with OA for subsequent follow-up. 


\section{Epidemiological and clinical data}

The questionnaire included age, sex, and profession. The data from the standard statistical survey questionnaire were logged in Microsoft Excel 2010 software. The 431 blood samples were stored in accordance with unified standards $\left(-80^{\circ} \mathrm{C}\right)$. We collected clinical information from medical records and radiological diagnoses.

\section{SNP selection and genotyping}

Twelve loci from $M M P-3$ and TIMP-3 were randomly selected for our study. Minor allele frequencies (MAF) of 4 loci were greater than 5\% in the HapMap of the Chinese Han Beijing population. DNA was extracted from $5 \mathrm{ml}$ of whole EDTA-blood using the phenolchloroform extraction method and was quantified using high performance liquid chromatography (NanoDrop2000; Thermo Fisher Scientific, Waltham, MA, USA) [37]. The DNA was then stored at $-20^{\circ} \mathrm{C}$ before genotyping. Sequenom MassARRAY Assay Design 3.0 Software was used to design the multiplexed SNP MassEXTENDED assay (Sequenom, Inc., San Diego, CA, USA). Genotyping was done according to the standard protocol recommended by the manufacturer. Table 4 shows the primers used for genotyping the 12 loci from MMP-3 and TIMP3. SequenomTyper 4.0 software was used for the data analysis [38].

\section{Statistical analysis}

Microsoft Excel 2010 software and SPSS 20.0 statistical software were for the statistical analysis of the data, including Hardy-Weinberg equilibrium analysis of the control group and $\chi^{2}$ test. All $p$ values were two-sided. The association between the risk of OA and the genotypes was assessed by calculating odds ratios (ORs) and $95 \%$ confidence intervals (95\% CIs) using unconditional logistic regression analysis. The statistical results of this study were reviewed by Fengjiao Wang from the Xi'an Tiangen Precision Medical Institute.

\section{ACKNOWLEDGMENTS}

This work was supported by the Social Development Program by Department of Science and Technology of Shaanxi Province (No. 2013K12-1402 ). The authors declare that they have no competing interests. We thank all of the participants for their involvement in this study.

\section{CONFLICTS OF INTEREST}

The authors declare that they have no conflicts of interest.

\section{REFERENCES}

1. Schiraldi C, Stellavato A, de Novellis F, La Gatta A, De Rosa M. Hyaluronan viscosupplementation: state of the art and insight into the novel cooperative hybrid complexes based on high and low molecular weight HA of potential interest in osteoarthritis treatment. Clin Cases Miner Bone Metab. 2016; 13:36-37.

2. Dieppe PA, Lohmander LS. Pathogenesis and management of pain in osteoarthritis. Lancet. 2005; 365:965-973.

3. Musumeci G, Aiello FC, Szychlinska MA, Di Rosa M, Castrogiovanni P, Mobasheri A. Osteoarthritis in the XXIst century: risk factors and behaviours that influence disease onset and progression. Int J Mol Sci. 2015; 16:6093-6112.

4. Valdes AM, Doherty M, Spector TD. The additive effect of individual genes in predicting risk of knee osteoarthritis. Ann Rheum Dis. 2008; 67:124-127.

5. Walker JL, Harrison TC, Brown A, Thorpe RJ Jr, Szanton SL. Factors associated with disability among middle-aged and older African American women with osteoarthritis. Disability and health journal. 2016; 9:510-517.

6. Bravata V, Minafra L, Forte GI, Cammarata FP, Saporito M, Boniforti F, Lio D, Gilardi MC, Messa C. DVWA gene polymorphisms and osteoarthritis. BMC Res Notes. 2015; 8:30.

7. Nakki A, Rodriguez-Fontenla C, Gonzalez A, Harilainen A, Leino-Arjas P, Heliovaara M, Eriksson JG, Tallroth K, Videman T, Kaprio J, Saarela J, Kujala UM. Association study of MMP8 gene in osteoarthritis. Connect Tissue Res. 2016; 57:44-52.

8. Muraki S, Oka H, Akune T, Mabuchi A, En-yo Y, Yoshida M, Saika A, Suzuki T, Yoshida H, Ishibashi H, Yamamoto S, Nakamura K, Kawaguchi H, Yoshimura N. Prevalence of radiographic knee osteoarthritis and its association with knee pain in the elderly of Japanese population-based cohorts: the ROAD study. Osteoarthritis Cartilage. 2009; 17:1137-1143.

9. Wang T, Liang Y, Li H, Li H, He Q, Xue Y, Shen C, Zhang C, Xiang J, Ding J, Qiao L, Zheng Q. Single nucleotide polymorphisms and osteoarthritis: an overview and a metaanalysis. Medicine. 2016; 95:e2811.

10. Wang D, Zhou K, Chen Z, Yang F, Zhang C, Zhou Z, Pei F. The association between DVWA polymorphisms and osteoarthritis susceptibility: a genetic meta-analysis. Int J Clin Exp Med. 2015; 8:12566-12574.

11. Singh RJ, Mason JC, Lidington EA, Edwards DR, Nuttall RK, Khokha R, Knauper V, Murphy G, Gavrilovic J. Cytokine stimulated vascular cell adhesion molecule-1 (VCAM-1) ectodomain release is regulated by TIMP-3. Cardiovasc Res. 2005; 67:39-49.

12. Valimaki J, Uusitalo H. Matrix metalloproteinases (MMP1, MMP-2, MMP-3 and MMP-9, and TIMP-1, TIMP-2 and TIMP-3) and markers for vascularization in functioning and non-functioning bleb capsules of glaucoma drainage implants. Acta Ophthalmol. 2015; 93:450-456. 
13. Prideaux M, Staines KA, Jones ER, Riley GP, Pitsillides AA, Farquharson C. MMP and TIMP temporal gene expression during osteocytogenesis. Gene Expr Patterns. 2015; 18:29-36.

14. Srivastava P, Kapoor R, Mittal RD. Impact of MMP-3 and TIMP-3 gene polymorphisms on prostate cancer susceptibility in North Indian cohort. Gene. 2013; 530:273-277.

15. Morgan AR, Han DY, Lam WJ, Triggs CM, Fraser AG, Barclay M, Gearry RB, Meisner S, Stokkers P, Boeckxstaens GE, Ferguson LR. Genetic variations in matrix metalloproteinases may be associated with increased risk of ulcerative colitis. Human Immunol. 2011; 72:1117-1127.

16. Saratzis A, Bown MJ, Wild B, Nightingale P, Smith J, Johnson C, Melas N, Kitas GD. Association between seven single nucleotide polymorphisms involved in inflammation and proteolysis and abdominal aortic aneurysm. J Vasc Surg. 2015; 61:1120-1128.e1121.

17. Rai MF, Schmidt EJ, Hashimoto S, Cheverud JM, Sandell LJ. Genetic loci that regulate ectopic calcification in response to knee trauma in $\mathrm{LG} / \mathrm{J}$ by $\mathrm{SM} / \mathrm{J}$ advanced intercross mice. J Orthop Res. 2015; 33:1412-1423.

18. Sakata S, Hayashi S, Fujishiro T, Kawakita K, Kanzaki N, Hashimoto S, Iwasa K, Chinzei N, Kihara S, Haneda M, Ueha T, Nishiyama T, Kuroda R, Kurosaka M. Oxidative stress-induced apoptosis and matrix loss of chondrocytes is inhibited by eicosapentaenoic acid. J Orthop Res. 2015; 33:359-365.

19. Yu WH, Yu S, Meng Q, Brew K, Woessner JF Jr. TIMP-3 binds to sulfated glycosaminoglycans of the extracellular matrix. J Biol Chem. 2000; 275:31226-31232.

20. Pavloff N, Staskus PW, Kishnani NS, Hawkes SP. A new inhibitor of metalloproteinases from chicken: ChIMP-3. A third member of the TIMP family. J Biol Chem. 1992; 267:17321-17326.

21. Nagase H, Woessner JF Jr. Matrix metalloproteinases. J Biol Chem. 1999; 274:21491-21494.

22. Suzuki H, Nezaki Y, Kuno E, Sugiyama I, Mizutani A, Tsukagoshi N. Functional roles of the tissue inhibitor of metalloproteinase 3 (TIMP-3) during ascorbate-induced differentiation of osteoblastic MC3T3-E1 cells. Biosci Biotechnol Biochem. 2003; 67:1737-1743.

23. Somerville RP, Oblander SA, Apte SS. Matrix metalloproteinases: old dogs with new tricks. Genome Biol. 2003; 4:216.

24. Birkedal-Hansen H, Moore WG, Bodden MK, Windsor LJ, Birkedal-Hansen B, DeCarlo A, Engler JA. Matrix metalloproteinases: a review. Crit Rev Oral Biol Med. 1993; 4:197-250.

25. Foster BP, Morse CI, Onambele GL, Williams AG. Variants within the MMP3 gene and patellar tendon properties in vivo in an asymptomatic population. Eur J Appl Physiol. 2014; 114:2625-2634.
26. Martin del Campo SE, Latchana N, Levine KM, Grignol VP, Fairchild ET, Jaime-Ramirez AC, Dao TV, Karpa VI, Carson M, Ganju A, Chan AN, Carson WE 3rd. MiR-21 enhances melanoma invasiveness via inhibition of tissue inhibitor of metalloproteinases 3 expression: in vivo effects of MiR-21 inhibitor. PLoS One. 2015; 10:e115919.

27. Dorecka M, Francuz T, Garczorz W, Siemianowicz K, Romaniuk W. The influence of elastin degradation products, glucose and atorvastatin on metalloproteinase-1, -2, -9 and tissue inhibitor of metalloproteinases-1, $-2,-3$ expression in human retinal pigment epithelial cells. Acta Biochim Pol. 2014; 61:265-270.

28. Kmiecik AM, Pula B, Suchanski J, Olbromski M, Gomulkiewicz A, Owczarek T, Kruczak A, Ambicka A, Rys J, Ugorski M, Podhorska-Okolow M, Dziegiel P. Metallothionein-3 increases triple-negative breast cancer cell invasiveness via induction of metalloproteinase expression. PLoS One. 2015; 10:e124865.

29. Han B, Wang HC, Li H, Tao YQ, Liang CZ, Li FC, Chen G, Chen QX. Nucleus pulposus mesenchymal stem cells in acidic conditions mimicking degenerative intervertebral discs give better performance than adipose tissue-derived mesenchymal stem cells. Cells Tissues Organs. 2014; 199:342-352.

30. Yuan LQ, Liu YS, Luo XH, Guo LJ, Xie H, Lu Y, Wu XP, Liao EY. Recombinant tissue metalloproteinase inhibitor-3 protein induces apoptosis of murine osteoblast MC3T3-E1. Amino Acids. 2008; 35:123-127.

31. Lee M, Aggen SH, Otowa T, Castelao E, Preisig M, Grabe HJ, Hartman CA, Oldehinkel AJ, Middeldorp CM, Tiemeier H, Hettema JM. Assessment and characterization of phenotypic heterogeneity of anxiety disorders across five large cohorts. Int J Methods Psychiatr Res. 2016; 25:255-266.

32. Murphy G, Nagase H. Progress in matrix metalloproteinase research. Mol Aspects Med. 2008; 29:290-308.

33. Javaid MA, Abdallah MN, Ahmed AS, Sheikh Z. Matrix metalloproteinases and their pathological upregulation in multiple sclerosis: an overview. Acta Neurol Belg. 2013; 113:381-390.

34. Euppayo T, Siengdee P, Buddhachat K, Pradit W, Chomdej S, Ongchai S, Nganvongpanit K. In vitro effects of triamcinolone acetonide and in combination with hyaluronan on canine normal and spontaneous osteoarthritis articular cartilage. In Vitro Cell Dev Biol Anim. 2016; 52:723-735.

35. Siengdee P, Euppayo T, Buddhachat K, Chomdej S, Nganvongpanit K. Two fluoroquinolones and their combinations with hyaluronan: comparison of effects on canine chondrocyte culture. J Vet Pharmacol Ther. 2016; 439:451.

36. Lee A, Park K, Choi SJ, Seo DH, Kim K, Kim HS, Choi K, Kwon IC, Yoon SY, Youn I. Prediction of antiarthritic drug efficacies by monitoring active matrix metalloproteinase-3 (MMP-3) levels in collagen-induced 
arthritic mice using the MMP-3 probe. Mol Pharm. 2014; 11:1450-1458.

37. Kochl S, Niederstatter H, Parson W. DNA extraction and quantitation of forensic samples using the phenolchloroform method and real-time PCR. Methods Mol Biol. 2005; 297:13-30.
38. Gabriel S, Ziaugra L, Tabbaa D. SNP genotyping using the Sequenom MassARRAY iPLEX platform. Current protocols in human genetics/editorial board, Jonathan L Haines [et al]. 2009; Chapter 2:Unit 2.12. 